\title{
Metabotropic Glutamate 5 Receptor (mGluR5) Antagonists Decrease Nicotine Seeking, But Do Not Affect the Reinforcement Enhancing Effects of Nicotine
}

\author{
Matthew I Palmatier*,', Xiu Liu', Eric C Donny', Anthony R Caggiula' and Alan F Sved ${ }^{2}$ \\ 'Department of Psychology, University of Pittsburgh, Pittsburgh, PA, USA; ${ }^{2}$ Department of Neuroscience, University of Pittsburgh, Pittsburgh, \\ PA, USA
}

\begin{abstract}
Nicotine self-administration models typically evaluate the effects of smoking cessation aides on 'primary reinforcement' engendered by nicotine. However, the more recently described reinforcement enhancing effects of the drug are not always included in experimental analyses of potential therapeutics. We evaluated the effects of pretreatment with noncompetitive antagonists of the metabotropic glutamate 5 receptor ( $m$ GluR5) on each reinforcement-related effect of nicotine using a model in which a reinforcing visual stimulus (VS) and nicotine infusions were concurrently available. Five groups (2-lever, VS-only, NIC + VS, NIC-only, or SAL-only) were instrumented for self-administration. The 2-lever group could earn a nicotine infusion $(0.06 \mathrm{mg} / \mathrm{kg}$ per infusion free base) for meeting the schedule on one lever (eg right), or VS for meeting the schedule on the other lever (eg left). The VS-only group could earn VS or saline under similar contingencies. Remaining rats could press one lever to earn both reinforcers (NIC + VS), nicotine infusions (NIC-only), or saline infusions (SAL-only); the other lever was 'inactive'. Responding on the VS lever in the 2-lever group was greater than that of the VS-only group, reflecting the reinforcement-enhancing effect of nicotine. Pretreatment with 2-methyl-6-(phenylethynyl)-pyridine (MPEP) or 3-[(2-methyl- I,3-thiazol-4-yl)ethynyl]pyridine (MTEP) decreased nicotine intake as well as the enhanced responding for the concurrently available VS. In follow-up studies, replacing nicotine via experimenter-administered infusions sustained the drugs reinforcement enhancing effect; neither MPEP nor MTEP decreased the enhancing effects of nicotine. These findings are consistent with other studies suggesting that $\mathrm{mGlu5}$ receptors mediate nicotine seeking, but do not alter the reinforcement enhancing effects of nicotine.

Neuropsychopharmacology (2008) 33, 2139-2147; doi:10.1038/s..npp. I301623; published online 28 November 2007
\end{abstract}

Keywords: nicotine; reinforcement; metabotropic; glutamate

\section{INTRODUCTION}

Therapeutic approaches to tobacco dependence are predicated on the assumption that nicotine is the primary reinforcement derived from tobacco; tobacco is consumed to obtain the pharmacological effect of nicotine, and this effect strengthens future tobacco consumption (USDHHS, 1988). Cessation therapies attempt to weaken tobacco consumption behavior by breaking its contingency with nicotine reinforcement. This is typically accomplished by eliminating, weakening, or devaluing the effects of the nicotine reinforcer (antagonism/extinction, Prignot, 1989; Stolerman, 1986), or by 'replacing' the reinforcer (or something similar) using a separate response (Jorenby et al, 1999, 2006; Rose et al, 1985). In either case the association between smoking and nicotine reinforcement is attenuated.

\footnotetext{
*Correspondence: Dr MI Palmatier, Department of Psychology, Kansas State University, 492 Bluemont Hall, I 100 Mid Campus Dr, Manhattan, KS 66502-5302, USA, Tel: 785532 06I3, Fax: 785532 540।,

E-mail: mattyp@ksu.edu

Received 16 May 2007; revised 17 September 2007; accepted 12 October 2007
}

Although bupropion and nicotine replacement therapies are currently the most successful clinical cessation aides, when they are used in preclinical models of nicotine selfadministration they have mixed effects (Bruijnzeel and Markou, 2003; Rauhut et al, 2003; Shoaib et al, 2003) or require extreme dosing (eg LeSage et al, 2002, 2003) that can sometimes interfere with ongoing behavior unrelated to nicotine seeking (Mansbach et al, 2000; Rauhut et al, 2003). One reason for this may be the complex motivational effects of nicotine; smoking (Rose et al, 2003) and nicotine selfadministration (Donny et al, 2003) are behaviors that depend on more than simple primary reinforcement by nicotine. For example, in rodent self-administration we have found that nicotine has a potent 'reinforcement enhancing' effect in which drug administration increases the rate of responding for reinforcing sensory stimuli (Chaudhri et al, 2006; Donny et al, 2003). This enhancing effect is thought to derive from a change in the reinforcing properties of the stimulus (Palmatier et al, 2007b).

One important aspect of the reinforcement enhancing effect of nicotine is that it could confound preclinical investigation of cessation aides. Traditionally, nicotine selfadministration in nonhuman subjects is 'cued', meaning 
that a sensory stimulus signals delivery of the infusion and/or a brief 'time-out' from further reinforcement. Investigating a therapeutic agent in this paradigm could be problematic if it had different effects on the primary reinforcing and reinforcement enhancing effects of nicotine. For example, a drug that reduces the motivation to take nicotine but does not alter the reinforcement derived from sensory stimuli or nicotine's enhancement of that reinforcement could lead to inconsistent or noninterpretable findings. Devaluation of nicotine reinforcement should decrease responding, but no change or inflation of stimulus reinforcement could counteract that effect and limit the impact of the pretreatment drug.

We have recently developed a preclinical model of selfadministration with more fidelity for the dual motivational effects of nicotine. In this paradigm, rats have concurrent access to two response options; making one response (eg pressing the left lever) results in nicotine delivery, making the other response (eg pressing the right lever) results in presentation of a reinforcing visual stimulus (VS). When these contingencies are in force, responding for nicotine occurs at low rates because the drug alone is a relatively weak reinforcement (Donny et al, 2003), whereas responding for VS occurs at higher rates than for a VS-only control group because VS-derived reinforcement is enhanced by the self-administered nicotine (Palmatier et al, 2006, 2007a). Using this model to dissociate the two reinforcementrelated effects of nicotine should isolate the nature of the effect of potential pharmacotherapies on operant behavior. For example, replacement therapies that decrease nicotine reinforcement and increase sensory reinforcement are expected to have opposite effects on each response option. However, in a self-administration paradigm, manipulations that decrease nicotine-intake would simultaneously attenuate a reinforcement enhancing effect; nicotine must be administered in order to observe the potentiating effect of the drug (Palmatier et al, 2007b). In such cases confirming that a manipulation selectively reduces nicotine seeking requires that the enhancing effects of nicotine are instantiated by a 'forced' nicotine administration (ie noncontingent infusion).

Using the concurrent access model, the present studies sought to investigate a potential novel pharmacotherapeutic target for smoking cessation, the metabotropic glutamate 5 receptor (mGluR5). Recent studies by Markou and colleagues (Harrison et al, 2002; Paterson and Markou, 2005; Paterson et al, 2003) suggest that the mGluR5 system may mediate primary reinforcement by nicotine, without impinging upon the reinforcement enhancing effects of drug administration. For example, administration of a selective antagonist, 2-methyl-6-(phenylethynyl)-pyridine (MPEP), decreased nicotine self-administration in rats and mice (Paterson et al, 2003) and decreased the motivation to take nicotine as measured on a progressive ratio schedule (Paterson and Markou, 2005). In contrast, MPEP did not alter nicotine's ability to lower intracranial self-stimulation thresholds (Harrison et al, 2002), suggesting the mGlu5 systems may not mediate the reinforcement enhancing effects of nicotine. To further examine the potential selectivity of mGlu5 systems for primary reinforcement by nicotine, rats with concurrent access to nicotine and VS were pretreated with MPEP. The effects of a more potent and selective mGluR5 antagonist 3-[(2-methyl-1,3-thiazol4-yl)ethynyl]pyridine (MTEP, Cosford et al, 2003) were also investigated.

\section{METHOD}

\section{Subjects}

Male Sprague-Dawley rats (Harlan Farms, Indianapolis, IN, USA) that weighed $174-200 \mathrm{~g}$ on arrival were housed individually in wire mesh cages in a temperature- and humidity-controlled colony room that was on a reverse $12: 12 \mathrm{~h}$ light: dark cycle. Rats were given unrestricted access to food and water for 7 days after their arrival, food access was subsequently restricted to $20 \mathrm{~g}$ per day allowing limited growth throughout the remainder of the study (Donny et al, 1995).

\section{Apparatus}

All experimental sessions were conducted in $25 \times 31 \times 28$ $(w \times l \times h) \mathrm{cm}^{3}$ operant conditioning chambers (BRS/LVE Model RTC-020, MD; see Donny et al, 1995 for further details). The compound VS was a 1-s illumination of the white cue light located directly above the 'VS' or 'active' lever, followed by 1-min deactivation of the house light. During each session rats were connected to a swivel system that allowed intravenous infusions to be delivered while also allowing free movement within the chamber.

\section{Drugs}

Nicotine hydrogen tartrate salt (Sigma, St Louis, MO), MPEP, and MTEP were dissolved in 0.9\% saline; MPEP was donated by the National Institute on Drug Abuse (Bethesda, MD; Experiment 1) or purchased from Sigma (Experiment 2), MTEP was donated by Eli Lilly \& Company (Indianapolis, IN). Nicotine solution $\mathrm{pH}$ was adjusted to $7.0( \pm 0.2)$ with a dilute $\mathrm{NaOH}$ solution. Nicotine was delivered at $0.06 \mathrm{mg} / \mathrm{kg}$ in a $0.1 \mathrm{ml} / \mathrm{kg}$ infusion; unit dose was calculated from the base form of nicotine. All nicotine infusions were delivered in less than $1 \mathrm{~s}$. MPEP and MTEP were injected into the intraperitoneal cavity (IP), MPEP was injected at a volume of $2 \mathrm{ml} / \mathrm{kg}$ and MTEP was injected at $1 \mathrm{ml} / \mathrm{kg}$.

\section{Procedure}

Lever training. Rats were autoshaped to press two levers for sucrose pellets as described previously (Palmatier et al, 2006). After a preference test for side bias, rats were randomly assigned to one of four groups (2-lever, NIC + VS, NIC-only, or VS-only), and each rat was randomly assigned an infusion and a VS lever or an active and an inactive lever, depending on group (see later). Lever preferences were counterbalanced as much as allowed by the samples and were matched across groups. Left $v s$ right lever preference ratios in each group were not statistically different, $\mathrm{F}<1$.

Surgery. Rats were implanted with chronic indwelling jugular catheters after lever training. Catheters were constructed and maintained as previously described (Donny et al, 1999). Catheter patency was established with 
$200 \mathrm{mg} / \mathrm{kg}$ infusions of chloral hydrate after the last antagonist testing sessions; rats that did not display symptoms of anesthesia within 1-min were excluded from analyses.

Acquisition. Self-administration testing began 10-14 days after surgery and was performed in 1-h sessions 5 days per week. Before each session, rats were placed in experimental chambers and connected to the drug-delivery system. Illumination of the house light and extension of the levers signaled the start of each session. For 2-lever groups, pressing the VS lever resulted in 1-s illumination of the cue light followed by 60 -s deactivation of the house light; pressing the VS-lever had no subsequent programmed consequence during this period. Pressing the infusion lever resulted in delivery of a nicotine infusion; subsequent infusions were not available until a 60-s time-out period had expired. Training contingencies were identical for the VSonly group except that pressing the infusion lever resulted in a $0.1 \mathrm{ml} / \mathrm{kg}$ saline infusion. NIC $+\mathrm{VS}$ groups received a $0.06 \mathrm{mg} / \mathrm{kg}$ nicotine infusion and VS for pressing the active lever. In contrast, NIC-only groups could only earn a $0.06 \mathrm{mg} / \mathrm{kg}$ nicotine infusion for pressing the active lever. A SAL-only control group was included in Experiment 2. For these rats, pressing the active lever resulted in a $0.1 \mathrm{ml} / \mathrm{kg}$ saline infusion. For the NIC + VS, NIC-only, and SAL-only groups pressing the inactive lever had no scheduled consequences. The reinforcement schedule began at a fixed ratio of 1 (FR1, sessions 1-12), and was increased to FR2 during all remaining testing sessions. For rats with two active levers (2-lever and VS-only), the schedule of reinforcement had to be met on each lever to receive the appropriate reinforcement (infusion or VS), the schedule on each lever was always identical and was equivalent to groups with one active lever (NIC + VS and NIC-only; see Palmatier et al, 2006 for more details). In order to habituate the rats to the injection protocol, each subject was administered an IP injection of saline $30 \mathrm{~min}$ before each of the last three sessions (sessions 20-22).

\section{Specific Experiments}

Table 1 provides a schematic representation of the groups, subject numbers, and drug pretreatment tests for each of the specific experiments. Each experiment included separate subjects and data were analyzed independently.

Experiment 1: MPEP dose. Initial tests with MPEP evaluated the relationship between test dose and responding for nicotine, VS, or both. Accordingly, nicotine infusions and VS presentations were available for meeting the operant schedule on the appropriate lever during these tests. Rats received IP MPEP $(3,6$, or $12 \mathrm{mg} / \mathrm{kg}) 30 \mathrm{~min}$ before testing on sessions 23, 26, and 29. Dosing order for each subject was based on a Latin Square. On intervening sessions (sessions $24-25,27-28$, and $30-31$ ) rats were pretreated with $0.9 \%$ saline (IP) in order to sustain steady-state behavior and to determine whether the test compounds had any cumulative or nonspecific effects that persisted for more than $24 \mathrm{~h}$. Data from these intervening tests were pooled for each subject and served as the $0 \mathrm{mg} / \mathrm{kg}$ test dose for each compound after determining that there were no persistent effects.
Table I Groups, Number of Subjects, and Testing Procedures for Each Experiment

\begin{tabular}{|c|c|c|c|}
\hline Experiment & Group (n) & $\begin{array}{l}\text { Maintenance } \\
\text { test sessions }\end{array}$ & $\begin{array}{l}\text { NIC } \\
\text { replacement } \\
\text { test sessions }\end{array}$ \\
\hline I & $\begin{array}{l}\text { 2-Lever (8) } \\
\text { NIC+VS (9) } \\
\text { VS-only (I0) }\end{array}$ & $\begin{array}{l}0,3,6 \text {, or } \\
12 \mathrm{mg} / \mathrm{kg} \text { MPEP } \\
\text { (Sessions 23, } \\
26, \text { and 29) }\end{array}$ & - \\
\hline 2 & $\begin{array}{l}\text { 2-Lever (I0) } \\
\text { NIC+VS (I0) } \\
\text { NIC-only (I0) } \\
\text { VS-only (6) } \\
\text { SAL-only (7) }\end{array}$ & - & $\begin{array}{l}0 \text { or } 12 \mathrm{mg} / \mathrm{kg} \\
\text { MPEP (Session } \\
23 \text { or } 26)+8 \mathrm{NIC} \\
\text { or SAL infusions }\end{array}$ \\
\hline 3 & $\begin{array}{l}\text { 2-Lever (6) } \\
\text { NIC+VS (9) } \\
\text { NIC-only (7) } \\
\text { VS-only (7) }\end{array}$ & $\begin{array}{l}\text { 0, I, 2, or } \\
4 \mathrm{mg} / \mathrm{kg} \text { MTEP } \\
\text { (Sessions 23, } \\
\text { 26, and 29) }\end{array}$ & - \\
\hline 4 & $\begin{array}{l}\text { 2-Lever (I0) } \\
\text { NIC+VS (I I) } \\
\text { NIC-only (7) } \\
\text { VS-only (7) }\end{array}$ & - & $\begin{array}{l}0 \text { or } 2 \mathrm{mg} / \mathrm{kg} \\
\text { MTEP (session } \\
32 \text { or } 35)+8 \mathrm{NIC} \\
\text { or SAL infusions }\end{array}$ \\
\hline
\end{tabular}

Abbreviations: MPEP, 2-methyl-6-(phenylethynyl)-pyridine (injected IP 30 min before test sessions); MTEP, 3-[(2-methyl- I,3-thiazol-4-yl)ethynyl]pyridine (injected IP $30 \mathrm{~min}$ before test sessions); NIC, nicotine (0.06 mg/kg/infusion). VS, compound visual stimulus (I-s stimulus light on followed by I-min house light off);

- Indicates subjects did not participate in the antagonist test.

Experiment 2: Effects of MPEP with nicotine replacement. In Experiment 1 MPEP reduced nicotine intake and responding for VS (see Results). Since we had shown previously that removing nicotine immediately abolishes the reinforcement enhancing effect (Palmatier et al, 2007b), it was unclear if MPEP directly attenuated the reinforcement enhancing effect of nicotine in the present study or if responding for the stimulus decreased because nicotineintake decreased. Subsequent tests evaluated the effect of MPEP $(12 \mathrm{mg} / \mathrm{kg}$, Experiment 2) on responding when nicotine infusions were 'replaced' (ie experimenter administered). During the test sessions, rats that previously had access to VS (2-lever, VS-only, and NIC+VS groups) continued to have access to VS for making a response on the appropriate lever. However, infusions were controlled by the experimenter and no longer available for pressing the infusion/active lever. Eight nicotine (2-lever, NIC + VS, and NIC-only groups) or saline (VS-only group) infusions were administered across the first 40 min of the test session according to a schedule that replicated, on average, the intervals at which $0.06 \mathrm{mg} / \mathrm{kg}$ nicotine is self-administered in the 2-lever and NIC-only group (Palmatier et al, 2006). Note that the VS-only condition tests for nonspecific effects of MPEP with a suitable operant baseline (eg comparable to 
NIC-only group). As a result, the SAL-only group was excluded from antagonist tests and the subjects with patent catheters were used to collect exploratory data for another study.

Nicotine replacement tests occurred on sessions 23 and 26 and were split across two sessions so that, within each group, half of the subjects received IP injections of the test compound before session 23 (MPEP test), and IP injections of saline before session 26 (saline test). For the remaining rats, test order of was reversed (ie saline first, MPEP second). In order to maintain steady state behavior, the intervening sessions (eg sessions 24-25) were preceded by $0.9 \%$ saline injection and reinforcement contingencies were identical to Acquisition; nicotine or saline infusions and/or VS were available for meeting the schedule on the appropriate lever. Data from these intervening sessions were pooled and served as a 'self-administration' control so that the effects of nicotine replacement and antagonist pretreatment could be evaluated independently.

Experiment 3: MTEP dose. Experiment 3 was identical to Experiment 1 except than rats were pretreated 1,2, or $4 \mathrm{mg} / \mathrm{kg}$ MTEP in sessions 23, 26, or 29.

Experiment 4: Effects of MTEP with nicotine replacement. The tests for this experiment were performed on later sessions (sessions 32 and 35) because Experiments 3 and 4 were conducted simultaneously. Therefore, the doseresponse relationship established for MTEP in Experiment 3 (sessions 23-31) was used to select a pretreatment dose in the nicotine replacement tests (sessions 32 and 35). Experiments 3 and 4 each used separate subjects; rats were randomly assigned to one of the experiments on day 23 (end of acquisition) with the constraint that response rate and reinforcers earned was matched across studies.

\section{Data Analyses}

Analyses of response rates were similar to Palmatier et al (2006). Nicotine-seeking and VS-seeking were analyzed independently. Active-lever responding for the NIC + VS group was included in both sets of analyses. The SAL-only control group was also included in both sets of analyses as a 'nonreinforced' control group. Omnibus analyses (including all independent factors and repeated conditions) for acquisition included group as a between subjects factor and session as a within subjects factor. In Experiments 1 and 3 (MPEP/MTEP dose tests), group and dose were the independent factors. For Experiments 2 and 4 (nicotine replacement tests), group and test served as the independent factors. Follow-up $t$-tests prompted by significant interactions included Boferroni's correction for alpha inflation (eg $p=0.05 / 12$ comparisons). Dunnett's $t$-tests were used to contrast responding in control groups (eg SAL-only) with experimental groups when omnibus ANOVA revealed a significant group effect involving more than two conditions. F-values and degrees of freedom are reported in Tables 2 and 3. An a priori $\alpha$ criterion was set at $p \leqslant 0.05$ for all comparisons; multiple $p$-values are reported as ' $p$ 's'.

\section{RESULTS}

\section{Acquisition}

Analyses of responding during the acquisition phase used data collected from rats in Experiment 2 because this experiment included a SAL-only comparison group. Similar patterns were observed in the other experiments. The SALonly group served as a nonreinforced control and was therefore included in both analyses of nicotine-seeking and VS-seeking.

Nicotine-seeking. During acquisition, rats with access to nicotine (NIC+VS, 2-lever, and NIC-only) responded at higher rates on the nicotine-associated lever relative to rats with access to saline infusions (SAL-only; Figure 1). Responding for nicotine decreased or did not change across FR1 sessions depending on group (group $\times$ session interaction, $p<0.001)$. Follow-up tests demonstrated that infusion-lever responding was similar in all groups during the first six sessions $(p$ 's $\geqslant 03)$. Rats in the NIC + VS group responded more on the active lever than SAL-only controls from sessions 7-12 ( $p$ 's0.002). For 2-lever and NIC-only groups responding for nicotine infusions did not differ from active-lever responding in SAL-only controls during FR1 sessions ( $p$ 's $\geqslant 0.013$ ). During FR2 sessions, active-lever (NIC-only group) and nicotine-lever (2-lever group) responding was significantly higher than active-lever responding in SAL-only controls ( $p$ 's $\leqslant 0.01)$.

VS-seeking. The reinforcement enhancing effects of nicotine were evidenced by an increase in responding for VS when rats had concurrent access to nicotine (2-lever group), relative to rats responding for VS with concurrent access to saline infusions (VS-only group). During initial FR1 sessions, responding on the VS-associated lever in all groups (2-lever, NIC + VS, and VS-only) was similar to SAL-only controls. However, as FR1 testing progressed,

Table 2 F-Values and Degrees of Freedom for Analyses of Responses During Acquisition (Experiment 2)

\begin{tabular}{|c|c|c|c|c|}
\hline & \multicolumn{2}{|c|}{ Nicotine-seeking ${ }^{a}$} & \multicolumn{2}{|c|}{ VS-seeking $^{\mathbf{b}}$} \\
\hline & df & $\mathbf{F}$ & df & $\mathbf{F}$ \\
\hline \multicolumn{5}{|l|}{ FR I (sessions 1-12) } \\
\hline Group & 3,33 & $4.7 I^{* * *}$ & 3,29 & $4.73^{*} *$ \\
\hline Session & 11,363 & $8.26 * *$ & 11,319 & 6.08 **** \\
\hline Group $\times$ session & 33,363 & $2.27 * *$ & 33,319 & $5.33 * *$ \\
\hline \multicolumn{5}{|l|}{ FR 2 (sessions 13-22) } \\
\hline Group & 3,33 & $21.72 * *$ & 3,29 & 10.24 *** \\
\hline Session & 9,297 & 1.33 & 9,261 & $1.98 *$ \\
\hline Group $\times$ session & 27, 297 & 0.53 & 27,261 & 1.02 \\
\hline
\end{tabular}

*** $p \leqslant 0.01, * p \leqslant 0.05$.

ancludes responses that result in nicotine infusion (2-lever, NIC+VS, and NIC-only groups) or saline (SAL-only group).

'Includes responses that result in VS presentation (2-lever, NIC+VS, and VS-only groups) or saline (SAL-only group). The SAL-only group is included in both sets of analyses as a 'nonreinforcement' control. 
Table 3 F-Values and Degrees of Freedom for Analyses of Responses During Antagonist Tests

\begin{tabular}{|c|c|c|c|c|c|}
\hline \multirow[t]{2}{*}{ Experiment } & & \multicolumn{2}{|c|}{ Nicotine-seeking ${ }^{a}$} & \multicolumn{2}{|c|}{ VS-seeking ${ }^{\mathbf{b}}$} \\
\hline & & df & $\mathbf{F}$ & df & $\mathbf{F}$ \\
\hline \multicolumn{6}{|l|}{ MPEP dose } \\
\hline & Group & 1,15 & |1.67**⿻丷木 & 2,24 & $7.15 * *$ \\
\hline \multirow[t]{2}{*}{ I } & Dose & 3,45 & |5.77*** & 3,72 & $17.18 * *$ \\
\hline & Group $\times$ dose & 3,45 & 0.77 & 6,72 & $3.09 * *$ \\
\hline
\end{tabular}

$\begin{array}{llrrrr}\text { MPEP+NIC } & & & & & \\ 2 & \text { Group } & 2,27 & 18.03 * * & 2,23 & 7.65 * * \\ & \text { Test } & 2,54 & 48.57 * * & 2,46 & 9.53 * * \\ & \text { Group } \times \text { test } & 4,54 & 4.21 * * * & 4,46 & 8.15 * *\end{array}$

MTEP dose

$\begin{array}{llcrr}\text { Group } & 2,19 & 4.78 * & 2,19 & 6.00 * * \\ \text { Dose } & 3,57 & 25.23 * * & 3,57 & 41.30 * * \\ \text { Group } \times \text { dose } & 6,57 & 0.34 & 6,57 & 5.34 * *\end{array}$

MTEP+NIC

$\begin{array}{llcccc}\text { Group } & 2,25 & 17.22 * * & 2,25 & 6.95 * * \\ & \text { Test } & 2,50 & 16.86 * * & 2,50 & 5.48 * * \\ & \text { Group } \times \text { test } & 4,50 & 0.67 & 4,50 & 3.73 * *\end{array}$

*** $p \leqslant 0.01, * p \leqslant 0.05$.

ancludes responses on the lever associated with nicotine infusion, 2-lever and $\mathrm{NIC}+\mathrm{VS}$ groups for Experiment I (MPEP dose) and 2-lever, NIC+VS, and NIConly groups in Experiment 3 (MTEP Dose).

${ }^{b}$ Includes responses that result in VS presentation (2-lever, NIC+VS, and VSonly groups). SAL-only group was not included in this phase of Experiment 2.
VS-seeking increased in 2-lever and NIC+VS groups relative to the SAL-only group (group $\times$ session interaction, $p<0.001$ ). This was confirmed by follow-up tests demonstrating that VS-lever responding in the 2-lever group differed from SAL-only controls on sessions $10-12$ $(p$ 's $\leqslant 0.003)$; active-lever responding for the NIC + VS group differed from SAL-only controls on sessions 7-12 (see Nicotine-seeking). For the VS-only group, VS-lever responding on an FR1 did not differ from active-lever responding in the SAL-only group ( $p$ 's $\geqslant 0.045$ ). During FR2 sessions this pattern was sustained (main effect of group, $p=0.002$ ); however the VS-only group responded significantly more on the VS-lever, relative to active-lever responding in the SAL-only group $(p=0.02)$.

\section{MPEP and MTEP Dose (Experiments 1 and 3)}

These tests evaluated the effects of various doses of MPEP (Experiment 1) and MTEP (Experiment 3) on nicotine seeking (ie responding on the nicotine-associated lever) and VS seeking (ie responding on the VS-associated lever) in each group. The description of analyses has been separated according to construct (nicotine- or VS-seeking) for ease of presentation.

Nicotine-seeking. Pretreatment with MPEP (Figure 2a) significantly reduced nicotine seeking in these tests (main effect of dose, $p<0.001)$. Follow-up tests confirmed that $12 \mathrm{mg} / \mathrm{kg}$ MPEP decreased responding on the nicotineassociated lever in the 2-lever and NIC+VS groups $(p$ 's $\leqslant 0.001)$. Despite a lower baseline of nicotine-lever responding, the 2-lever group was more sensitive to this effect of MPEP, as the $6 \mathrm{mg} / \mathrm{kg}$ dose significantly decreased responding on the nicotine lever $(p=0.003)$. A similar

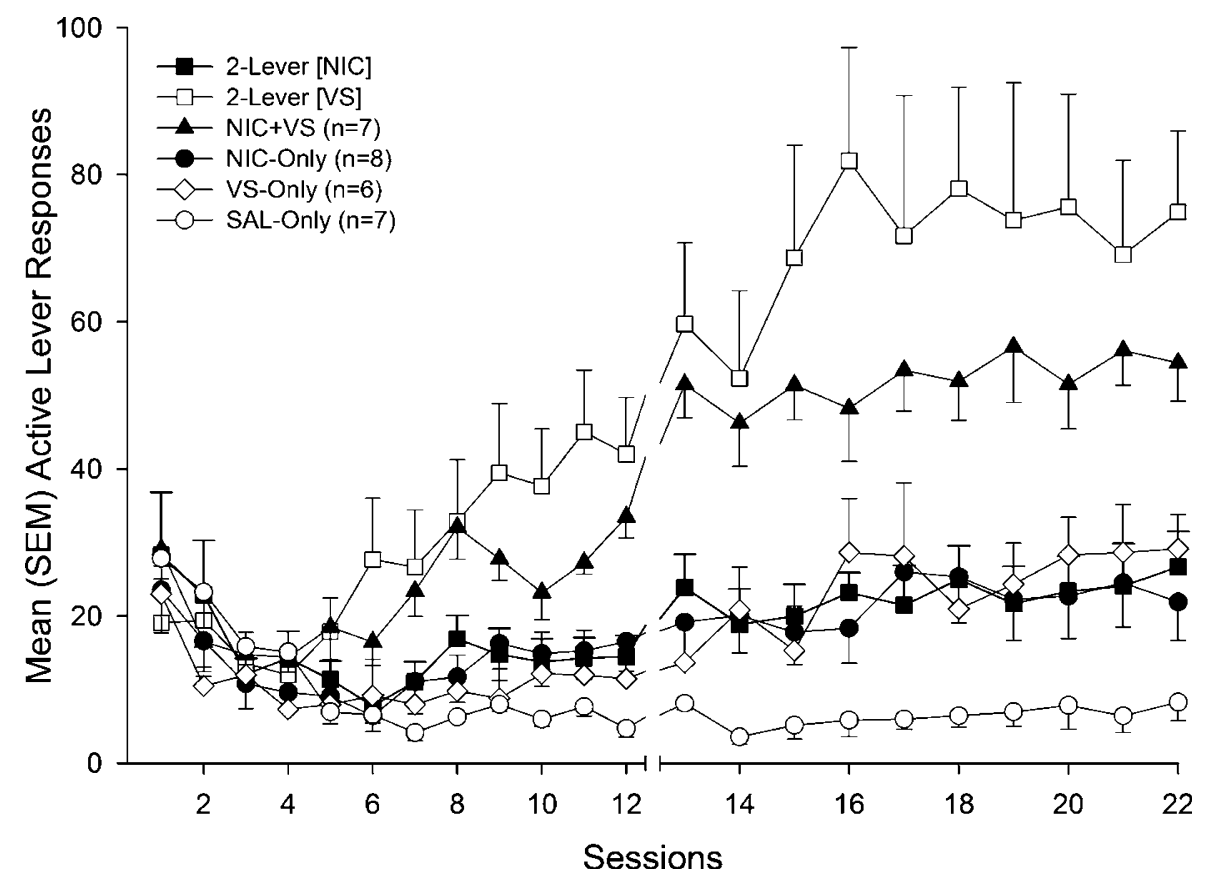

Figure I Mean ( \pm SEM) active lever responding for rats with concurrent access to nicotine and a reinforcing visual stimulus (VS, 2-lever group), rats that received both reinforcers for pressing a single active lever (NIC + VS group), groups that only received access to one of the reinforcers (VS-only or NIC-only groups), and a nonreinforced control condition (SAL-only group). Nicotine (NIC-only vs SAL-only) and VS (VS-only vs SAL-only) both served as primary reinforcers when they were self-administered in isolation (sessions 12-22), and self-administered nicotine enhanced responding for VS (VS-only vs 2-lever). 
pattern of results emerged for MTEP pretreatment (Figure 2b), there was a dose-dependent decrease in nicotine seeking (main effect of dose, $p<0.001$ ). Pretreatment with 2 or $4 \mathrm{mg} / \mathrm{kg}$ MTEP decreased responding on the nicotine-associated lever in the 2-lever, NIC-only, and NIC + VS groups ( $p$ 's $\leqslant 0.008)$.

VS-seeking. MPEP (Figure 2a) dose dependently decreased responding for VS in groups that demonstrated a reinforcement enhancing effect of nicotine (group $\times$ dose interaction, $p=0.01)$. As illustrated in Figure 2a, MPEP did not affect responding in the VS-only group ( $p$ 's $\geqslant 0.39$ ). However, VSlever responding was significantly reduced by $12 \mathrm{mg} / \mathrm{kg}$ MPEP in the NIC + VS and 2-lever groups $(p$ 's $<0.001)$ and reached levels not significantly different from the VS-only group. This pattern was nearly identical for rats pretreated with MTEP (Figure $2 \mathrm{~b}$, group $\times$ dose interaction, $p<0.001$ ). Pretreatment with 2 and $4 \mathrm{mg} / \mathrm{kg}$ MTEP decreased responding on the VS-associated lever for rats in the NIC + VS and 2 -lever groups ( $p$ 's $\leqslant 0.006)$, but did not decrease responding for the VS-only group $(p=0.61)$.

\section{Effects of MPEP and MTEP with Nicotine Replacement (Experiments 2 and 4 )}

In the MPEP and MTEP dose tests, the parallel attenuation of nicotine and VS-seeking could be the result of a direct effect of the antagonists (ie mGluR5 mediates the reinforcement enhancing effect of nicotine) or an indirect effect of decreased nicotine self-administration (ie no reinforcement enhancing effect is expected if nicotine is not selfadministered). To investigate these hypotheses, rats were pretreated with an mGluR5 antagonist $(12 \mathrm{mg} / \mathrm{kg}$ MPEP in Experiment 2, $2 \mathrm{mg} / \mathrm{kg}$ MTEP in Experiment 4) or vehicle $30 \mathrm{~min}$ before test sessions in which the normal contingencies were in place, but rats received experimenter-administered nicotine.

Nicotine-seeking. Pretreatment with MPEP (Figure 3a) significantly reduced nicotine seeking in the nicotine replacement tests (main effect of test, $p<0.001$ ). As illustrated in Figure 3a, pretreatment with $12 \mathrm{mg} / \mathrm{kg}$ MPEP (black bars) decreased the nicotine-associated response, relative to pre-test response rates (open bars), in the 2-lever, NIC-only, and NIC + VS groups ( $p$ 's $\leqslant 0.02)$. Experimenter administered nicotine did not disrupt nicotine seeking in any group; response rates on the saline test (hatched bars) did not differ from the pre-test control ( $p$ 's $\geqslant 0.33)$. A similar pattern emerged for rats pretreated with $2 \mathrm{mg} / \mathrm{kg}$ MTEP (Figure 3b), the significant effect of test $(p<0.001)$ was specific to MTEP pretreatment in all three groups $(p$ 's $\leqslant 0.04)$ and there was no effect of experimenteradministered nicotine on nicotine seeking $\left(p^{\prime} s \geqslant 0.71\right)$. Notably, MPEP caused a disproportionate decrease in active-lever responding for the NIC + VS group (grouptest interaction, $p=0.01$ ), this could have been the result of a nonspecific effect of MPEP on operant responding. Notably, this pattern was not confirmed in parallel tests with the more selective and potent compound (MTEP).

VS-seeking. Pretreatment with MPEP (Figure 3a) only decreased VS seeking when this measure was confounded with nicotine seeking (NIC + VS group). Inclusion of the $\mathrm{NIC}+\mathrm{VS}$ group resulted in a significant group $\times$ test interaction ( $p=0.002$, Figure $3 a)$ in the Omnibus ANOVA; for these rats VS-seeking on the MPEP test differed significantly from responding on pre-test sessions $(p=0.008)$. Neither experimenter-administered nicotine nor MPEP pretreatment affected VS seeking in the 2-lever group, VS-lever responding on the pre-test did not differ from responding on the MPEP $\left(p^{\prime} s=0.56\right)$ or saline $(p ' s \geqslant 0.79)$ tests. The VS-only group confirmed that MPEP pretreatment did not have any nonspecific effects on responding or reinforcement by VS $(p=0.66)$. A similar pattern emerged for rats pretreated with $2 \mathrm{mg} / \mathrm{kg}$ MTEP (Figure 3b); the significant group $\times$ test interaction $(p=0.01)$ demonstrated that MTEP pretreatment decreased responding only in the NIC + VS group ( $p$ 's $=0.02)$. For the 2-lever group, self-administered and experimenter-administered nicotine produced statistically similar effects on VS-lever responding $(p=0.18)$ and the enhancing effect of nicotine was not attenuated by $\operatorname{MTEP}(p=0.98)$ in this
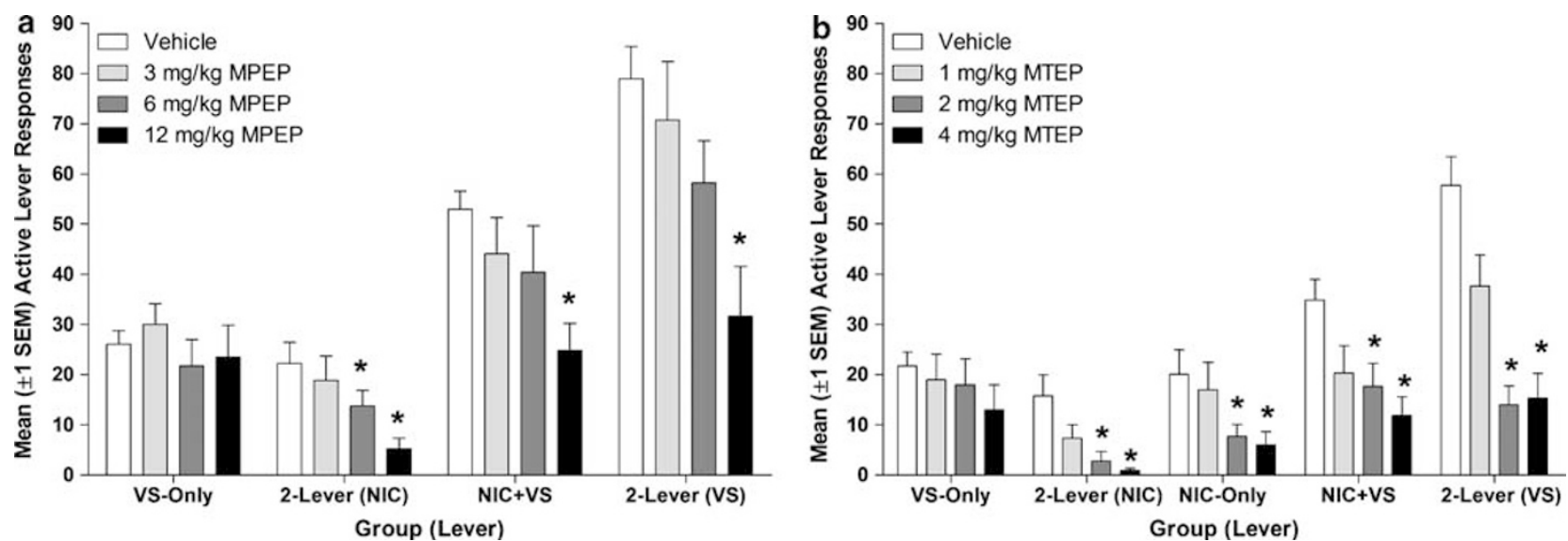

Figure 2 Panel (a) illustrates mean ( + SEM) active lever responding for groups tested with various doses of MPEP (Experiment I). Panel (b) illustrates mean (+ SEM) active lever responding for groups tested with various doses of MTEP (Experiment 3). Both metabotropic glutamate 5 receptor (mGluR5) antagonists dose dependently decreased nicotine seeking. Neither antagonist decreased responding for VS (VS-only group), unless VS-derived reinforcement was inflated by concurrent (2-lever group) or contingent (NIC + VS group) access to nicotine. 

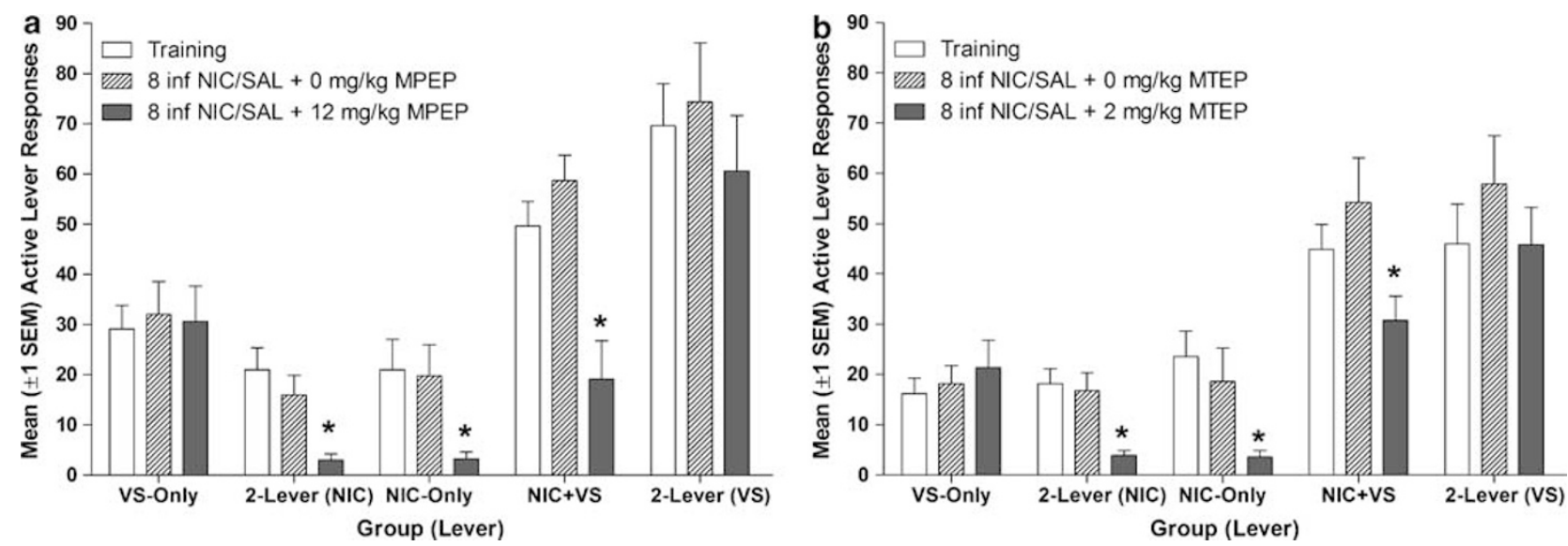

Figure 3 Panel (a) illustrates mean ( + SEM) active lever responding for groups tested with nicotine replacement and 0 or $12 \mathrm{mg} / \mathrm{kg}$ MPEP (Experiment 2). Panel (b) illustrates mean (+SEM) active lever responding for groups tested with nicotine replacement and 0 or 2 mg/kg MTEP (Experiment 4). Since both mGluR5 antagonists reduced voluntary nicotine-intake (see Figure 2), evaluating their impact on the reinforcement enhancing effects of nicotine required experimenter-administered infusions. Thus, rats in the 2-lever, NIC + VS, and NIC-only groups were given eight experimenter-administered infusions of nicotine during the 60-min test period, the VS-only group received eight saline infusions (hatched and solid bars, see Method). The antagonists decreased nicotine seeking but did not affect the reinforcement enhancing effects of nicotine. Both metabotropic glutamate 5 receptor (mGluR5) antagonists dose dependently decreased nicotine seeking. Neither antagonist decreased VS seeking when VS was presented in isolation (VS-only group), or when VS seeking and nicotine seeking were measured with separate/concurrent responses (2-lever group). Rats in the saline-only (Experiment 2) were not included in pharmacological tests.

group. The VS-only group confirmed that pretreatment with $2 \mathrm{mg} / \mathrm{kg}$ MTEP did not affect motor activity or VS-derived reinforcement $(p=0.18)$.

\section{DISCUSSION}

We have suggested that nicotine acts in two distinct ways to promote self-administration in preclinical models and tobacco consumption in humans (Chaudhri et al, 2006). First, nicotine directly strengthens operant responding (primary reinforcing effect, see Chaudhri et al, 2006). Second, nicotine enhances the incentive value of reinforcing nonpharmacological stimuli (Chaudhri et al, 2006; Donny et al, 2003; Palmatier et al, 2006). The dual reinforcing effects of nicotine raise important questions about pharmacological smoking cessation aides, namely, how do these therapies affect these two distinct actions of nicotine? The present studies were designed to examine the role of a potential pharmacotherapeutic target, mGlu5 receptors, on the two reinforcement related effects of nicotine. Two new findings emerged that may benefit the development of smoking cessation aides. First, nicotine seeking depends on glutamatergic activity at mGlu5 receptors. Second, the reinforcement enhancing effects of nicotine do not depend on signaling at these receptors.

Metabotropic glutamate receptors include eight subtypes that have been divided into three groups according to G-protein coupling and sequence homology: group I (mGluR1, 5), group II (mGluR2-3), and group III (mGluR4, 6-8; Conn and Pin, 1997). The moderate to high density localization of mGlu5 receptors in the frontal cortex, striatum, nucleus accumbens, and hippocampus (Marino et al, 2002; Marino and Conn, 2002), as well as their modulatory role in membrane excitability in these regions (eg Domenici et al, 2003) has made them a target of interest for pharmacotherapeutic intervention in substance dependence (Chiamulera et al, 2001) and obesity (Bradbury et al,
2005). Noncompetitive antagonists of mGluR 5 decrease selfadministration of cocaine (Kenny et al, 2005), ethanol (Cowen et al, 2005), and nicotine (Paterson and Markou, 2005; Paterson et al, 2003). Many of these studies suggest that mGlu5 receptors mediate drug reinforcement and reward-related learning (see also Bäckström and Hyytiä, 2007). However, including the present experiments, all demonstrations that mGlu5 compounds decrease drug self-administration occur in acute tests, suggesting that the mGlu5 compounds reduce the anticipatory motivational valence of the drug effect (ie 'wanting', Robinson and Berridge, 1993), rather than the ability of the drug to strengthen or sustain operant responding per se.

Refinements in drug self-administration protocols have used progressive ratio (Roberts and Richardson, 1992) and chain schedules of operant behavior in attempts to evaluate 'motivation to take a drug' and dissociate 'drug-seeking/ appetitive' responses from 'drug-taking/consummatory' responses (Olmstead et al, 2000; Samson et al, 1998). Although these methods do not necessarily separate 'wanting' from 'liking/reinforcing' (Berridge, 2007), they provide additional measures of drug seeking that are less confounded by satiation and nonspecific post-administration drug effects. Using these procedures, a recent study demonstrated that MTEP decreased both the appetitive/ seeking and consummatory/taking components of ethanol self-administration in C57BL/J6 mice (Cowen et al, 2007). Additionally, MPEP decreased progressive ratio break points for nicotine and cocaine self-administration in rats, suggesting that it decreased the motivation to obtain a drug infusion (Paterson and Markou, 2005). Therefore, despite the problems dissociating motivation from reinforcement in the self-administration paradigm, the emerging pattern suggests that mGluR5s mediate the motivation to obtain a drug, rather than the post-administration reinforcing effect. Although the present studies did not specifically evaluate 'motivation' with one of the aforementioned paradigms, our findings are consistent with the hypothesis that MPEP and 
MTEP decreased the motivation to obtain nicotine. Both drugs decreased responding on the nicotine lever when infusions were contingent upon the operant response (Experiments 1 and 3), or when nicotine was administered by the experimenter (Experiments 2 and 4). However, neither of the two antagonists altered nicotine's ability to enhance the reinforcement derived from other non-nicotine stimuli.

Although initial tests suggested that the mGluR5 antagonists decreased the reinforcement enhancing effects of nicotine in Experiments 1 and 3, the accompanying decrease in nicotine intake confounded this conclusion. When self-administration of nicotine was 'replaced' by experimenter administration in Experiments 2 and 4, the reinforcement enhancing effects were sustained and these effects were not disrupted by MPEP or MTEP. Similarly, Markou and colleagues found that MPEP decreased nicotine self-administration but did not alter the facilitative effects of nicotine on brain-reward function as assessed by intracranial self-stimulation (ICSS) threshold (Kenny et al, 2003). Although these findings seem to be complementary, we have previously argued that parallels between ICSS and sensory reinforcement should be made judiciously (Palmatier et al, 2007b). For example, the present findings that blockade of mGlu5 receptors did not affect responding for sensory reinforcement per se, may contrast with recent findings from the ICSS paradigm showing that MPEP decreased brain reward function (eg Liechti and Markou, 2007). Arguably, a change in brain reward function induced by the mGluR 5 antagonists should have been accompanied by a decrease, or possibly a compensatory increase, in responding for sensory reinforcement (VS-only group). Since a change in ICSS threshold is a direct measure of current brain reward function (Markou and Koob, 1992), it would undoubtedly be more sensitive to changes in brain reward than sensory reinforcement. Future studies should investigate the potential convergent and divergent information provided by ICSS threshold and sensory reinforcement models. For example, ICSS threshold may be an important measure of the affective consequences of drug administration/withdrawal, whereas sensory reinforcement may be more related to the cognitive enhancing effects of drugs.

In summary, negative allosteric modulators of mGlu5 receptors decreased nicotine seeking, but did not disrupt the reinforcement enhancing effects of nicotine administration. Given the fidelity of the concurrent access model for dissociating the two reinforcement-related effects of nicotine, this paradigm may be considered a useful preclinical screen for potential smoking cessation aides. Arguably, negative allosteric modulators of mGluR5 represent potential therapeutics that do not interfere with nicotine's ability to enhance mood (ie decrease ICSS threshold, Harrison et al, 2002) or to enhance cognitive function (ie reinforcement enhancing effects, present studies). A treatment that could reduce nicotine seeking without altering the mood- or cognitive-enhancing effects of nicotine (eg MTEP) could be an effective adjunct to current replacement therapies.

\section{ACKNOWLEDGEMENTS}

We thank Sheri Booth, Maysa Gharib, Laure Craven, Gina Matteson, and Kara Mays for their assistance in conducting the studies. MTEP was donated by Eli Lilly \& Company; MPEP used in Experiment 1 was donated by the NIDA drug supply. All experiments followed the 'Principles of laboratory animal care' (NIH \#85-23, revised 1985) and were approved by the University of Pittsburgh Institutional Animal Care and Use Committee (Assurance \# A3187-01). This research was supported by NIH grants DA-10464, DA-19278, and DA-17288.

\section{DISCLOSURE/CONFLICT OF INTEREST}

The research presented in this manuscript was supported by NIH Grants DA-10464, DA-19278, and DA-17288. For Experiments 1, 3, and 4, pretreatment drugs were donated by the National Institute on Drug Abuse (MPEP) and Eli Lilly \& Company (MTEP). The authors declare that, except for income received from our primary employers, no financial support or compensation has been received from any individual or corporate entity over the past 3 years for research or professional service and there are no personal financial holdings that could be perceived as constituting a potential conflict of interest.

\section{REFERENCES}

Bäckström P, Hyytiä P (2007). Involvement of AMPA/kainate, NMDA, and mGlu5 receptors in the nucleus accumbens core in cue-induced reinstatement of cocaine seeking in rats. Psychopharmacology 192: 571-580.

Berridge KC (2007). The debate over dopamine's role in reward: the case for incentive salience. Psychopharmacology 191: 391-431.

Bradbury MJ, Campbell U, Giracello D, Chapman D, King C, Tehrani L et al (2005). Metabotropic glutamate receptor mGlu5 is a mediator of appetite and energy balance in rats and mice. J Pharmacol Exp Ther 313: 395-402.

Bruijnzeel AW, Markou A (2003). Characterization of the effects of bupropion on the reinforcing properties of nicotine and food in rats. Synapse 50: 20-28.

Chaudhri N, Caggiula AR, Donny EC, Palmatier MI, Liu X, Sved AF (2006). Complex interactions between nicotine and nonpharmacological stimuli reveal multiple roles for nicotine in reinforcement. Psychopharmacology 184: 353-366.

Chiamulera C, Epping-Jordan MP, Zocchi A, Marcon C, Cottiny C, Tacconi $S$ et al (2001). Reinforcing and locomotor stimulant effects of cocaine are absent in mGluR5 null mutant mice. Nat Neurosci 4: 873-874.

Conn PJ, Pin JP (1997). Pharmacology and functions of metabotropic glutamate receptors. Annu Rev Pharmacol Toxicol 37: 205-237.

Cosford ND, Tehrani L, Roppe J, Schweiger E, Smith ND, Anderson J et al (2003). 3-[(2-Methyl-1,3-thiazol-4-yl)ethynyl]pyridine: a potent and highly selective metabotropic glutamate subtype 5 receptor antagonist with anxiolytic activity. $J$ Med Chem 46: 204-206.

Cowen MS, Djouma E, Lawrence AJ (2005). The metabotropic glutamate 5 receptor antagonist 3-[(2-methyl-1,3-thiazol-4yl)ethynyl]-pyridine reduces ethanol self-administration in multiple strains of alcohol-preferring rats and regulates olfactory glutamatergic systems. J Pharmacol Exp Ther 315: 590-600.

Cowen MS, Krstew E, Lawrence AJ (2007). Assessing appetitive and consummatory phases of ethanol self-administration in C57BL/ $6 \mathrm{~J}$ mice under operant conditions: regulation by mGlu5 receptor antagonism. Psychopharmacology 190: 21-29. 
Domenici MR, Pintor A, Potenza RL, Gaudi S, Gro MC, Passarelli F et al (2003). Metabotropic glutamate receptor 5 (mGluR5)mediated phosphoinositide hydrolysis and NMDA-potentiating effects are blunted in the striatum of aged rats: a possible additional mechanism in striatal senescence. Eur J Neurosci 17: 2047-2055.

Donny EC, Caggiula AR, Knopf S, Brown C (1995). Nicotine selfadministration in rats. Psychopharmacology 122: 390-394.

Donny EC, Caggiula AR, Mielke MM, Booth S, Gharib MA, Hoffman A et al (1999). Nicotine self-administration in rats on a progressive ratio schedule of reinforcement. Psychopharmacology 147: 135-142.

Donny EC, Chaudhri N, Caggiula AR, Evans-Martin FF, Booth S, Gharib MA et al (2003). Operant responding for a visual reinforcer in rats is enhanced by noncontingent nicotine: implications for nicotine self-administration and reinforcement. Psychopharmacology 169: 68-76.

Harrison AA, Gasparini F, Markou A (2002). Nicotine potentiation of brain stimulation reward reversed by $\mathrm{DH}$ beta $\mathrm{E}$ and $\mathrm{SCH}$ 23390, but not by eticlopride, LY 314582 or MPEP in rats. Psychopharmacology (Berl) 160: 56-66.

Jorenby DE, Hays JT, Rigotti NA, Azoulay S, Watsky EJ, Williams $\mathrm{KE}$, et al, Varenicline Phase 3 Study G (2006). Efficacy of varenicline, an alpha4beta2 nicotinic acetylcholine receptor partial agonist, vs placebo or sustained-release bupropion for smoking cessation: a randomized controlled trial [see comment] [erratum appears in JAMA. 2006 Sep 20; 296 (11):1355]. JAMA 296: 56-63.

Jorenby DE, Leischow SJ, Nides MA, Rennard SI, Johnston JA, Hughes AR et al (1999). A controlled trial of sustained-release bupropion, a nicotine patch, or both for smoking cessation. $N$ Engl J Med 340: 685-691.

Kenny PJ, Boutrel B, Gasparini F, Koob GF, Markou A (2005). Metabotropic glutamate 5 receptor blockade may attenuate cocaine self-administration by decreasing brain reward function in rats. Psychopharmacology (Berl) 179: 247-254.

Kenny PJ, Paterson NE, Boutrel B, Semenova S, Harrison AA, Gasparini $\mathrm{F}$ et al (2003). Metabotropic glutamate 5 receptor antagonist MPEP decreased nicotine and cocaine self-administration but not nicotine and cocaine-induced facilitation of brain reward function in rats. Ann NY Acad Sci 1003: 415-418.

LeSage MG, Keyler DE, Collins G, Pentel PR (2003). Effects of continuous nicotine infusion on nicotine self-administration in rats: relationship between continuously infused and selfadministered nicotine doses and serum concentrations. Psychopharmacology 170: 278-286.

LeSage MG, Keyler DE, Shoeman D, Raphael D, Collins G, Pentel PR (2002). Continuous nicotine infusion reduces nicotine selfadministration in rats with $23-\mathrm{h} /$ day access to nicotine. Pharmacol Biochem Behav 72: 279-289.

Liechti ME, Markou A (2007). Interactive effects of the mGlu5 receptor antagonist MPEP and the mGlu2/3 receptor antagonist LY341495 on nicotine self-administration and reward deficits associated with nicotine withdrawal in rats. Eur J Pharmacol 554: 164-174.

Mansbach RS, Chambers LK, Rovetti CC (2000). Effects of the competitive nicotinic antagonist erysodine on behavior occasioned or maintained by nicotine: comparison with mecamylamine. Psychopharmacology 148: 234-242.

Marino MJ, Awad H, Poisik O, Wittmann M, Conn PJ (2002). Localization and physiological roles of metabotropic glutamate receptors in the direct and indirect pathways of the basal ganglia. Amino Acids 23: 185-191.
Marino MJ, Conn JP (2002). Modulation of the basal ganglia by metabotropic glutamate receptors: potential for novel therapeutics. Curr Drug Targets CNS Neurol Disord 1: 239-250.

Markou A, Koob GF (1992). Construct validity of a self-stimulation threshold paradigm: effects of reward and performance manipulations. Physiol Behav 51: 111-119.

Olmstead MC, Parkinson JA, Miles FJ, Everitt BJ, Dickinson A (2000). Cocaine-seeking by rats: regulation, reinforcement and activation. Psychopharmacology 152: 123-131.

Palmatier MI, Evans-Martin FF, Hoffman A, Caggiula AR, Chaudhri N, Donny EC et al (2006). Dissociating the primary reinforcing and reinforcement-enhancing effects of nicotine using a rat self-administration paradigm with concurrently available drug and environmental reinforcers. Psychopharmacology 184: 391-400.

Palmatier MI, Liu X, Caggiula AR, Donny EC, Sved AF (2007a). The role of nicotinic acetylcholine receptors in the primary reinforcing and reinforcement-enhancing effects of nicotine. Neuropsychopharmacology 32: 1098-1108.

Palmatier MI, Matteson GL, Black JJ, Liu X, Caggiula AR, Craven L et al (2007b). The reinforcement enhancing effects of nicotine depend on the incentive value of non-drug reinforcers and increase with repeated drug injections. Drug Alcohol Depend 89: 52-59.

Paterson NE, Markou A (2005). The metabotropic glutamate receptor 5 antagonist MPEP decreased break points for nicotine, cocaine and food in rats. Psychopharmacology 179: 255-261.

Paterson NE, Semenova S, Gasparini F, Markou A (2003). The mGluR5 antagonist MPEP decreased nicotine self-administration in rats and mice. Psychopharmacology 167: 257-264.

Prignot J (1989). Pharmacological approach to smoking cessation. Eur Respir J 2: 550-560.

Rauhut AS, Neugebauer N, Dwoskin LP, Bardo MT (2003). Effect of bupropion on nicotine self-administration in rats. Psychopharmaco$\log y$ 169: 1-9.

Roberts DCS, Richardson NR (1992). Self-administration of psychomotor stimulants using progressive ratio schedules of reinforcement. In: Boulton A, Baker $\mathrm{G}$, Wu $\mathrm{PH}$ (eds). Neuromethods: Animal Models of Drug Addiction. Humana Press: Clifton, pp 233-269.

Robinson TE, Berridge KC (1993). The neural basis of drug craving: an incentive-sensitization theory of addiction. Brain Res Brain Res Rev 18: 247-291.

Rose JE, Behm FM, Westman EC, Bates JE, Salley A (2003). Pharmacologic and sensorimotor components of satiation in cigarette smoking. Pharmacol Biochem Behav 76: 243-250.

Rose JE, Herskovic JE, Trilling Y, Jarvik ME (1985). Transdermal nicotine reduces cigarette craving and nicotine preference. Clin Pharmacol Ther 38: 450-456.

Samson HH, Slawecki CJ, Sharpe AL, Chappell A (1998). Appetitive and consummatory behaviors in the control of ethanol consumption: a measure of ethanol seeking behavior. Alcohol Clin Exp Res 22: 1783-1787.

Shoaib M, Sidhpura N, Shafait S (2003). Investigating the actions of bupropion on dependence-related effects of nicotine in rats. Psychopharmacology 165: 405-412.

Stolerman IP (1986). Could nicotine antagonists be used in smoking cessation? Br J Addict 81: 47-53.

USDHHS (1988). Nicotine addiction: a report of the surgeon general. In: US Department of Health and Human Services, Office of the Assistant Secretary for Health OoSaH (eds). 